\title{
Carnosine: can understanding its actions on energy metabolism and protein homeostasis inform its therapeutic potential?
}

\author{
Alan R Hipkiss", Stephanie P Cartwright, Clare Bromley, Stephane R Gross and Roslyn M Bill
}

\begin{abstract}
The dipeptide carnosine ( $\beta$-alanyl-L-histidine) has contrasting but beneficial effects on cellular activity. It delays cellular senescence and rejuvenates cultured senescent mammalian cells. However, it also inhibits the growth of cultured tumour cells. Based on studies in several organisms, we speculate that carnosine exerts these apparently opposing actions by affecting energy metabolism and/or protein homeostasis (proteostasis). Specific effects on energy metabolism include the dipeptide's influence on cellular ATP concentrations. Carnosine's ability to reduce the formation of altered proteins (typically adducts of methylglyoxal) and enhance proteolysis of aberrant polypeptides is indicative of its influence on proteostasis. Furthermore these dual actions might provide a rationale for the use of carnosine in the treatment or prevention of diverse age-related conditions where energy metabolism or proteostasis are compromised. These include cancer, Alzheimer's disease, Parkinson's disease and the complications of type-2 diabetes (nephropathy, cataracts, stroke and pain), which might all benefit from knowledge of carnosine's mode of action on human cells.
\end{abstract}

Keywords: Carnosine, Energy metabolism, Reactive oxygen species (ROS), Methylglyoxal, Proteolysis, Alzheimer's disease, Parkinson's disease, Diabetes, Cancer, Yeast

\section{Review}

\section{Carnosine and cellular ageing}

In 1994, McFarland and Holliday demonstrated that when the naturally-occurring dipeptide, carnosine (Figure 1), was added to cultures of primary human fibroblast cells, chronological lifespan was increased; the onset of senescence was effectively delayed in these cells [1]. Carnosine addition was also observed to rejuvenate already senescent cells, giving them a more juvenile appearance [1]. Paradoxically, a subsequent study revealed that carnosine selectively inhibited the growth of cancer cells, at least in culture [2]. Since explanatory mechanisms for these seemingly opposing effects are still unknown, carnosine has been called enigmatic [3].

Carnosine ( $\beta$-alanyl-L-histidine) was discovered over 100 years ago (see [4] for a historic account). It occurs naturally in the brain, kidney and skeletal muscle of fish, birds and mammals at concentrations sometimes as high as

\footnotetext{
* Correspondence: alanandjill@lineone.net; r.m.bill@aston.ac.uk

Aston Research Centre for Healthy Ageing, School of Life and Health Sciences, Aston University, Birmingham B4 7ET, UK
}

$100 \mathrm{mmol} \mathrm{kg}{ }^{-1}$ dry muscle mass [5]. Functionally carnosine appears to be pluripotent as there is evidence that it can scavenge reactive oxygen species (ROS) [6] and reactive nitrogen species (RNS) [7], can form adducts with deleterious aldehydes and ketones [8-11] and can act as a metal ion chelator [12] and hydrogen ion buffer [13]. Carnosine has also been demonstrated to affect gene expression [14], protein phosphorylation [15] and, possibly, mRNA translation initiation through the regulation of the eukaryotic initiation factor 4E protein (eIF4E) [16]. Despite this range of properties, the actual physiological function of carnosine remains unknown.

The addition of carnosine to cells has been shown to result in three outcomes that are characteristic of longlived model systems [17]. These are decreased glycolysis, increased mitochondrial activity and suppression of proteotoxicity [17]. While these observations may hint at which of carnosine's diverse properties are responsible for increasing chronological lifespan, any mechanistic rationale must also account for carnosine's selective toxicity towards tumour cells. In this review, we discuss 


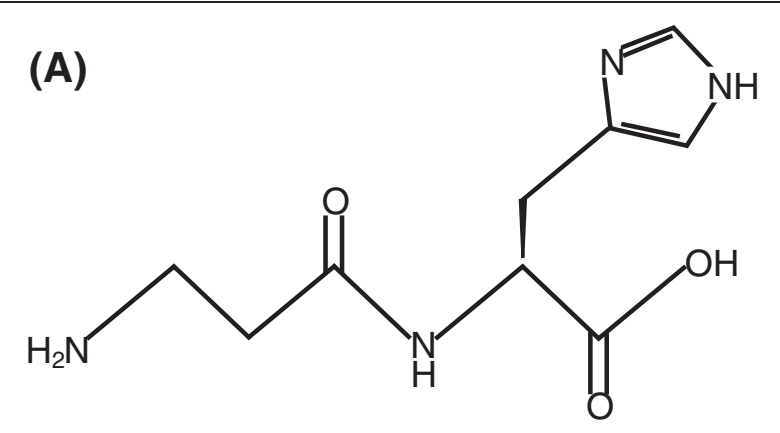

(B)

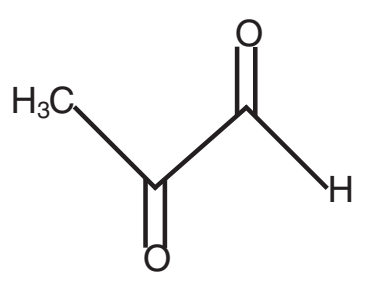

Figure 1 (A) Structure of L-carnosine, the dipeptide $\beta$-alanyl-Lhistidine; (B) structure of methylgloxal (2-oxopropanal).

mechanisms that could accommodate the uniquely disparate effects of carnosine on cellular activity.

\section{Carnosine and changes in energy metabolism Tumour cells, carnosine and glycolysis}

The metabolism of tumour cells is characteristically shifted towards cytosolic glycolysis [18,19], as first reported by Otto Warburg [20]. However, respiratory activity is not necessarily compromised $[21,22]$ and has recently been proposed to be central to cancer progression [23]. Consensus has yet to be reached on the reasons for these complex metabolic switches, but the high energy and macromolecular precursor demands of rapidly growing tumours may provide an explanation [24]. We speculate that carnosine's effects on tumour cells might be explained, in part, by its action on glycolysis (Figure 2). For example, whilst investigating the influence of carnosine on cultured brain tumour cells, Gaunitz and co-workers discovered that its addition inhibited cell growth due to the large decline in glycolytically-synthesized ATP $[25,26]$. Our own study in yeast (which can be used to model cancer cells [24]) led to the conclusion that carnosine may affect glycolysis [27]; addition of carnosine to yeast growing on glucose as sole carbon source, where the majority of ATP is generated from glycolysis, caused up to $20 \%$ cell death and a decreased overall growth rate. In contrast, cells growing aerobically on glycerol as sole carbon source were not inhibited by the addition of carnosine and showed an increased growth rate. Because glycerol is normally metabolized via dihydroxyacetone phosphate (DHAP) and glyceraldehyde 3-phosphate (G3P), these observations could support an interpretation that carnosine inhibits glycolysis prior to the formation of these triose phosphates from their glycolytic precursor, fructose 1,6-bisphosphate (Figure 2).

Unfortunately there is no evidence in the literature to demonstrate a direct effect on glycolysis by carnosine. However, in 1980, in vitro experiments on rabbit muscle demonstrated that both carnosine and histidine stimulate the activity of fructose 1,6-bisphosphatase (FBPase), which converts fructose 1,6-bisphosphate to fructose 6-phosphate [28] (Figure 2). The mechanism of this stimulation is unknown but, in the case of carnosine, could potentially be due to its ability to chelate the metal ions (such as $\mathrm{Zn}^{2+}$ and $\mathrm{Mg}^{2+}$ [12]), that regulate glycolytic enzymes [29]. For example, if carnosine addition were to activate FBPase in vivo by chelating $\mathrm{Zn}^{2+}$ [28], this would create a futile, ATP-consuming cycle since the ATP-utilizing enzyme phosphofructokinase converts fructose 6-phosphate into fructose 1,6-bisphosphate (Figure 2). This cycle would decrease ATP levels and ATP synthesis as well as decreasing the supply of carbon skeletons for amino acid synthesis. While this hypothesis is inconsistent with the fact that addition of histidine does not result in the death of glucose-grown yeast cells [27], it remains conceivable that carnosine's metal-chelating properties influence the function of one or more glycolytic enzymes.

\section{Carnosine and the metabolism of ageing cells}

The metabolic shifts that occur as organisms grow, mature and finally age are complex and incompletely understood. When rapid growth ceases, in the transition to adulthood, the preferred pathway for ATP generation changes from glycolysis to oxidative phosphorylation [17]. However, one hallmark of cellular ageing is increased mitochondrial dysfunction; this frequently leads to cells reverting to glycolysis for ATP generation [30]. Consequently, it is likely that a subtle balance in the regulation of glycolysis and oxidative phosphorylation is critical throughout the lifespan [31].

Literature reports indicate that post-mitotic, adult (and therefore typically less glycolytic) cells have higher carnosine concentrations than actively-dividing cells, although the reasons for this tendency are unknown. For example, during murine brain development, carnosine synthesis is only associated with the final stages of glial cell maturation [32]. Carnosine is also present only in post-mitotic retinal neurones [33] when energy metabolism switches from glycolysis to oxidative phosphorylation [31]. In children, muscle carnosine levels are initially quite low (30-40 $\mathrm{mg} \%$ ) at 5 years of age but, as they grow, gradually increase to $120-140 \mathrm{mg} \%$ at 14 years of age $[34,35]$ before declining and reaching a plateau in adulthood. Together these observations might suggest that carnosine is beneficial to adult cells (which employ oxidative phosphorylation for ATP generation), whereas in growing cells (which employ glycolysis to 


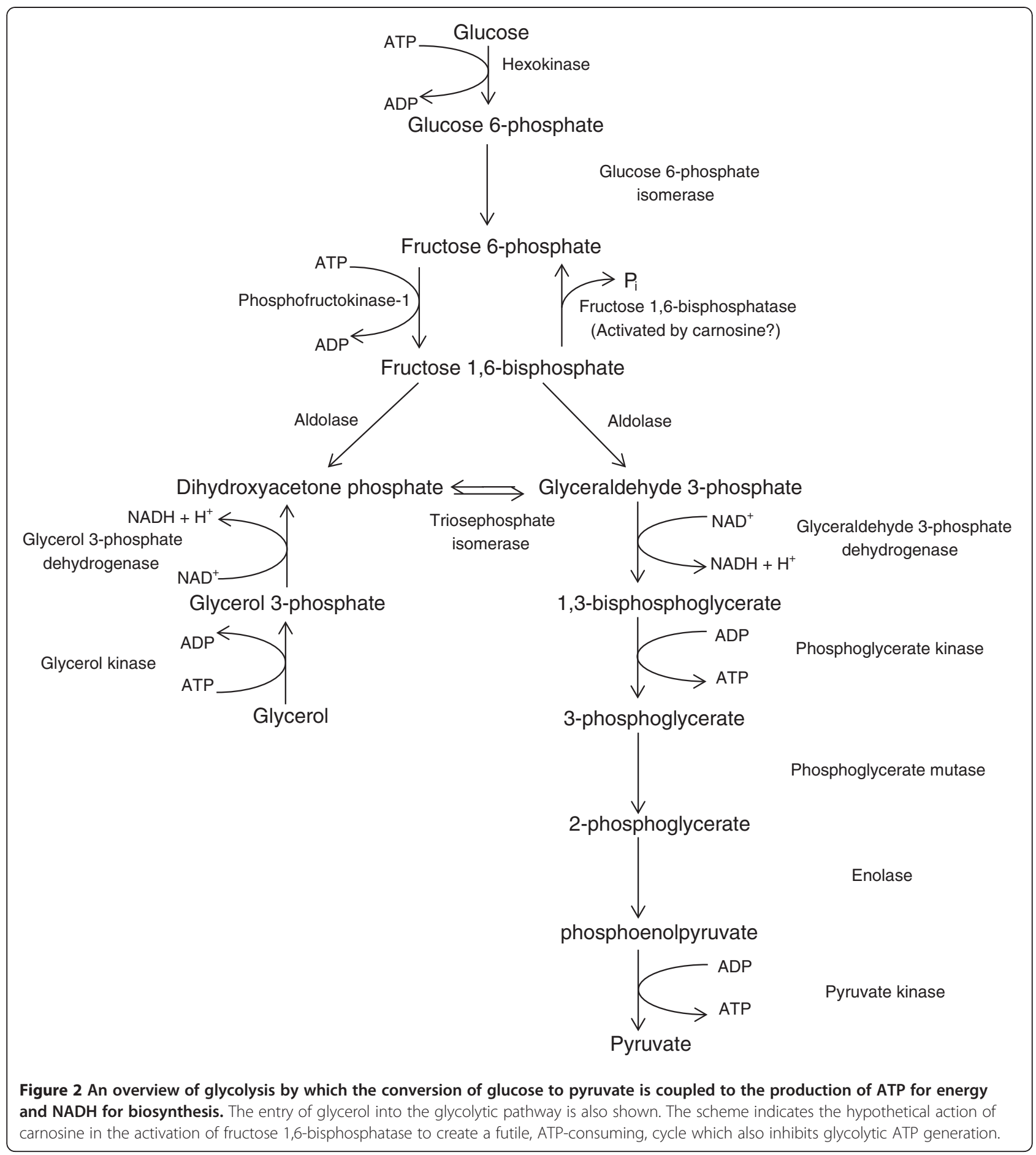

provide metabolic precursors and ATP), carnosine could even be detrimental. However, contrary to this suggestion, carnosine concentrations are higher in fast-twitch, glycolytic muscle than in slow-twitch, aerobic muscle [36]; this observation argues against the proposition that carnosine is more beneficial to aerobic cells than those that employ glycolysis to synthesize ATP. While any correlation between carnosine concentrations and metabolic state is unlikely to be clear cut, it has been suggested that high carnosine levels in adult (but not senescent) glycolytic tissue are required to maintain $\mathrm{pH}$ by buffering the high amounts of protons produced as a consequence of glycolytic activity (e.g. through lactic acid formation) and to combat the potentially deleterious by-products of glycolysis such as methylglyoxal (MG; Figure 1) [9]. 
It has also been noted that addition of carnosine to cultured rat fibroblasts strongly stimulates synthesis of the cytoskeletal protein, vimentin [14]; vimentin is closely, but not exclusively, involved with mitochondrial movement and localization [37]. Carnosine has also been observed to have a beneficial but unspecified organisational effect towards mitochondria [38]. One possibility is that the stimulation of vimentin synthesis by carnosine may in turn assist mitochondrial synthesis and intracellular targeting in ageing cells. These observations might support an interpretation that carnosine is associated with the metabolic rewiring that occurs when rapid growth declines and finally ceases, a change that is often accompanied by decreased glycolysis and increased mitochondrial activity. If carnosine were to positively influence mitochondrial development or activity, and also provide protection against deleterious glycolytic by-products (e.g. MG, especially following the reversion to glycolysis resulting from age-related mitochondrial damage in senescent tissues), this might help to explain the dipeptide's rejuvenating effects on senescent cultured human fibroblasts [1]; currently, this hypothesis remains to be tested.

\section{Carnosine and age-related changes in proteostasis}

Increased proteolytic activities (autophagic and proteasomal $[39,40])$ and the up-regulation of one or more heat shock and/or chaperone proteins are associated with lifespan extension in yeast [41], birds and mammals [42]; they help to maintain proteostasis by degrading altered proteins. Conversely, the accumulation of altered proteins (proteostatic dysfunction) is a major hallmark of ageing [43]. MG (Figure 1) is a well-characterized $\alpha$-ketoaldehyde whose toxic effects on cells and tissues closely mimic those of the ageing process. When serum glucose levels are raised, MG is increased [44] and is increasingly regarded as a major source of age-related protein damage and proteoxicity $[45,46]$ as it can form adducts, known as advanced glycation end-products (AGEs; Figure 3), with lysine, histidine, arginine and cysteine residues of target proteins. Increased formation of MG may also arise via the polyol pathway [47], which also generates glyceraldehyde and DHAP. If not immediately metabolized to 1,3-bisphosphoglycerate, these trioses spontaneously decompose into MG (Figure 3). Carnosine's ability to scavenge reactive species such as MG (and others such as malondialdehyde, a lipid peroxidation product) is well documented $[8,9,17,48]$ and might explain the dipeptide's ability to delay cellular senescence.

There is evidence that carnosine, either as the free dipeptide or when complexed with zinc ions (so-called polaprezinc), can induce expression of the heat shock proteins, Hsp 27 [49] and Hsp70/72 [50]. Other studies have also demonstrated that carnosine can stimulate a cytosolic protease [51] or indeed proteolysis of long-lived proteins in senescent cultured human fibroblasts [52]. Although these findings (some preliminary) seem to suggest that carnosine might help to maintain proteostasis, further experimentation is required to confirm this hypothesis.

The stimulation of vimentin synthesis in cultured rat fibroblasts by carnosine [14] may be relevant in this context as well. Vimentin has been suggested to participate in the formation of aggresomes into which protein aggregates are sequestered, especially when proteasomal activity is inhibited [53]; it has been proposed that vimentin forms a cage surrounding the target protein (which is frequently ubiquitinated) [54]. The enzyme, oxidized protein hydrolase $(\mathrm{OPH})$, is co-expressed with vimentin [55] raising the possiblity that $\mathrm{OPH}$ and vimentin co-operate to form aggresomes, which, together with proteasomes, facilitate the disposal of oxidized proteins [55] and thereby help to maintain proteostasis (Figure 4).

Recent studies have confirmed the view that maintenance of proteolytic function is important for regulating energy metabolism: 6-phosphofructo-2-kinase/fructose 2,6-bisphosphatase (Pfkfb3), which generates fructose 2,6-bisphosphate, is subject to continuous proteasome-

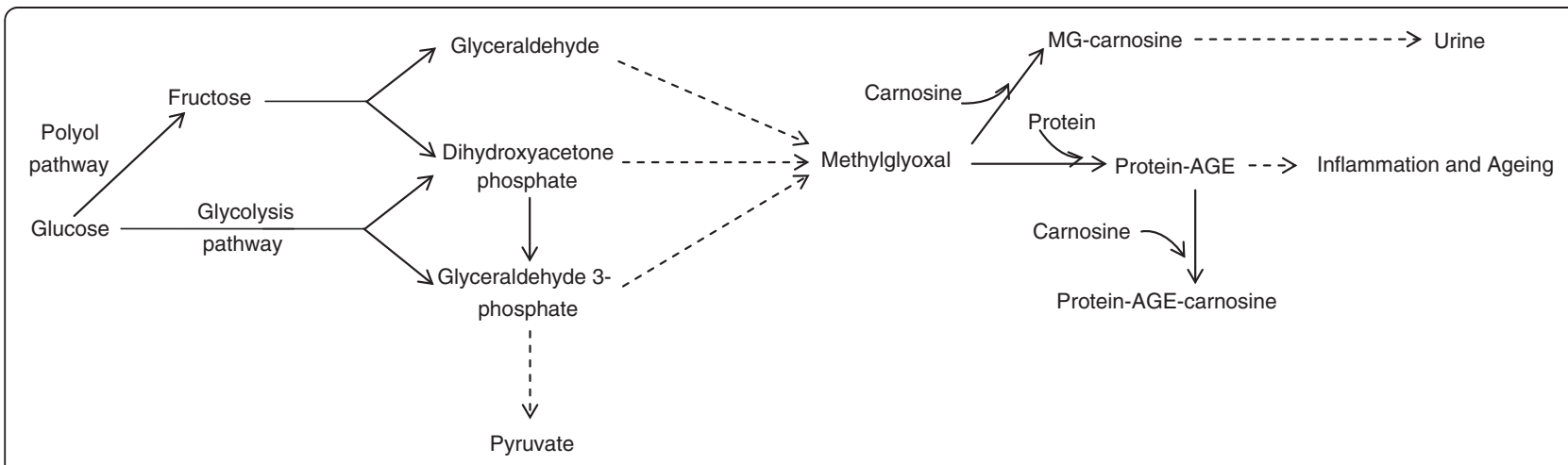

Figure 3 Metabolic sources of methylglyoxal (MG) and the possible role of carnosine in scavenging MG and suppressing the formation of protein-AGEs. Protein-AGEs cause inflammation and ageing. MG-carnosine is excreted in urine. 
mediated degradation following its ubiquitination $[56,57]$. However, if degradation of Pfkfb3 is inhibited, glycolysis is stimulated and oxidative stress results [56]; in neurones this provokes cell death [57]. Possible explanations for these findings are a reduced pentose phosphate pathway metabolism and/or increased MG formation following increased triose phosphate formation. Collectively these observations illustrate how proteostatic dysfunction can directly impact energy metabolism and vice versa [58]; excess MG formation may compromise the function of the ubiquitin/proteasome system [44], illustrating the delicate interdependence between energy metabolism and proteostasis.

\section{The therapeutic potential of carnosine}

As carnosine may possess activities that suppress age-related dysfunction in either energy metabolism or proteostasis [17], it has been proposed as a potential therapeutic agent [see [59] for recent review]. Indeed carnosine may resemble other naturally-occurring agents, such as resveratrol, that possess similar pluripotency [60] and therefore have the potential to be used as "smart drugs" that simultaneously act on multiple targets [61]. Carnosine is also well-documented to have antioxidant properties (see [4] for more information): it can scavenge reactive oxygen species such as hydroxyl radicals, superoxide and singlet oxygen [62]. Moreover, carnosine can chelate the heavy metals that cause cellular damage [63]. These properties protect macromolecules, such as lipids, proteins and DNA, from the damage which results in ageing and age-related disease [64].
While there are no current reports of clinical trials concerning carnosine's affects towards clinically-defined age-related dysfunction, it was recently reported that carnosine improved cognition in schizophrenics [65]. In senescence-accelerated mice, a diet supplemented with carnosine decreased the signs of ageing and increase mean lifespan by $20 \%$ [66].

\section{Cancer}

The ability of carnosine to suppress the growth of tumour cells has recently been reviewed [67], one possible mechanism being its inhibition of energy metabolism. Consistent with this is the finding that carnosine inhibits glycolytic ATP generation [25], although the mechanistic details underpinning this observation remain to be determined. Possibilities include the stimulation of FBPase activity, described above, effects on another glycolytic enzyme or its effects on the intracellular signalling cascades that regulate translational processes. For example, a reduction in phosphorylation of the translation initiation factor eIF4E [16] might alter the rate of mRNA initiation and consequently of protein synthesis [68]. Although a full picture is not currently available of the different intracellular mechanisms at play following carnosine treatment, initial evidence suggests that both mitogen-activated (MAP) kinase and mammalian target of rapamycin complex (mTOR) may be involved [16]. Our own work in Saccharomyces cerevisiae supports this idea since we have demonstrated that deletion of TOR1 confers resistance to carnosine treatment [27]. Further work is needed to decipher how eIF4E

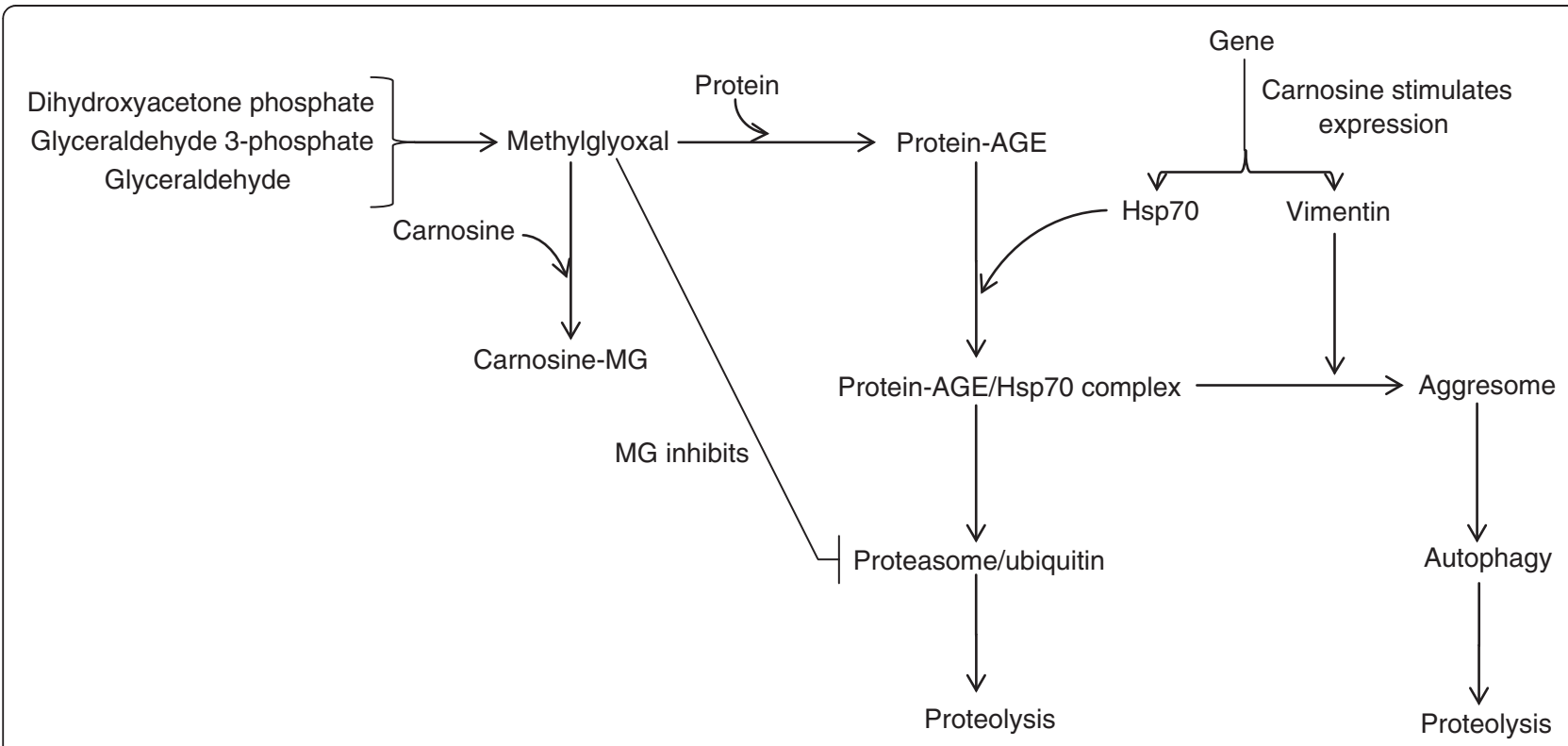

Figure 4 The possible effects of carnosine on the formation and catabolism of abnormal proteins. MG, methyglyoxal; AGE, advanced glycation end-product; Hsp70, heat shock protein 70 (shown as an example). 
activities might be regulated in response to carnosine. The eIF4E binding protein (eIF4E-BP) is of particular interest as it is known to be regulated by mTOR and is affected by the well-known anti-tumour and anti-ageing agents, rapamycin [69] and resveratrol [70].

AGEs, which are formed at an accelerated rate during normal ageing and in diabetics, have been shown to have a role in the development and progression of cancers; it is believed that through interaction with their receptor (RAGE) they stimulate pro-inflammatory gene activation and hence oxidative stress [71,72]. We have shown that carnosine inhibits the formation of AGEs: it can protect against MG modification [9] and significantly reduces the formation of protein-crosslinking and oxidative modification [59]. The ability of carnosine to prevent AGE formation has also been demonstrated by others both in vitro [73-75] and in vivo [48]; the plethora of signalling cascades activated include NF-kB, MAPKs, PI3K/Akt and the Rho GTPases. Direct evidence for a role for carnosine and AGE/RAGE in tumorigenesis is currently missing, but may provide new avenues of research to inhibit tumour growth.

\section{Alzheimer's disease}

There is extensive evidence from animal studies showing that carnosine is a neuroprotective agent [76]. Further evidence suggesting that carnosine might be used to control Alzheimer's disease (AD) $[77,78]$ includes its ability to suppress the toxic effects of amyloid beta towards cultured cells $[79,80]$ and to inhibit sugar-dependent protein aggregation [81]. Importantly carnosine was found to suppress the accumulation of amyloid in transgenic mice [82]; the mechanisms responsible are uncertain but could involve zinc ion modulation, up-regulation of heat shock protein expression, and/or enhanced proteolysis of the aberrant polypeptide. As there is a strong link between type- 2 diabetes and $\mathrm{AD}[60]$, the ability of carnosine to suppress glycation-related phenomena should also be explored in relation to $\mathrm{AD}$ [59].

Carnosine has been shown to suppress mitochondrial dysfunction in a transgenic mouse model of Alzheimer's disease [82] and is also an activator of carbonic anhydrase (CA), which is decreased in AZ patients [83]. The activity of some CA isozymes has been reported to decline in certain parts of the human brain with age [84] and silencing of the CA gene, cah-3, in the nematode Caenorhabditis elegans is reported to reduce lifespan [85].

\section{Parkinson's disease}

Preliminary studies have demonstrated beneficial effects of carnosine supplementation in PD patients [86,87]. Very recently it was found that in the brains of PD patients, the substantia nigra (the area subject to degeneration in PD), contains up to 3 times more non-specific cytosolic carnosinase, CNDP2 [88], compared to controls. If carnosine is normally protective in the substantia nigra, raised cellular carnosinase activity would lower that protection. This interpretation is supported by the finding that high glycemic index diets in mice raise MGdamaged protein levels in the substantia nigra [44]. That the substantia nigra is particularly susceptible to degeneration may derive from the fact that it synthesizes dopamine; it was recently shown that MG can spontaneously react with dopamine to produce 1-acetyl-6,7-dihydroxy1,2,3,4-tetrahydroisoquinoline (ADTIQ), which is found in brains affected by PD [89]. Importantly, carnosine has been shown to inhibit ADTIQ toxicity [90]. It is also possible that carnosine, by scavenging MG, could additionally inhibit ADTIQ formation. Overall, these findings suggest that carnosine could possess therapeutic potential towards PD [91].

\section{Diabetes-related diseases}

In type-2 diabetes patients, cataractogenesis [92], diabetic kidney disease [93] and atherosclerosis are common consequences [94] of MG-induced glycation of proteins, as well as other cellular dysfunction. It has also been recognised for some time that there is a relationship, possibly causal, between type-2 diabetes and AD [60]. A similar association may exist for type-2 diabetes and other age-related diseases such as PD [95-97]; again MG could be a major contributing or even causal factor [98].

As carnosine has been shown to exert protective activity against protein modification mediated by MG and other reactive carbonyls, the dipeptide has been explored for its therapeutic potential towards complications associated with type-2 diabetes [99]. Two recent studies have shown that diabetes-related peripheral algesia (pain) is mediated by the generation of MG in neural tissue $[100,101]$. Carnosine has been shown to possess antinociceptive activity (pain suppression) in mice [102,103], which could be due to the dipeptide's ability to react with MG. Hence it is possible that carnosine could be one of several therapeutic options in alleviating diabetesrelated pain.

\section{Carnosine administration: overcoming the carnosinase problem}

It is often thought that the presence of serum carnosinase in humans is an impediment to the therapeutic use of carnosine [59]; indeed reduced levels of carnosinase in serum have been suggested to reduce diabetic complications [104]. However, a number of strategies could overcome this perceived obstacle. These include using modified forms of L-carnosine resistant to carnosinase attack (e.g. $\mathrm{N}$-acetyl-carnosine); using an intra-nasal delivery route to combat neurodegeneration and brain tumours; 
and using $\mathrm{N}$-acetyl-carnosine-containing eye drops, which could be employed for treating cataracts.

\section{Conclusions}

Carnosine appears to have metabolism-dependent effects on cells and may inhibit ATP production during glycolysis. Carnosine also appears to facilitate the selective elimination of aberrant polypeptides and may stimulate the synthesis of stress proteins, thereby helping to maintain the proteome. By influencing two fundamental biochemical characteristics of the aged phenotype, energy metabolism and proteostasis, this intriguing dipeptide has the potential to ameliorate a range of age-related conditions.

\section{Abbreviations}

AD: Alzheimer's disease; ADTIQ: 1-acetyl-6,7-dihydroxy-1,2,3,4tetrahydroisoquinoline; CA: Carbonic anhydrase; DHAP: Dihydroxyacetone phosphate; elF4E: Eukaryotic initiation factor 4E protein; FBPase: Fructose 1,6bisphosphatase; G3P: Glyceraldehyde 3-phosphate; MAP: Mitogen-activated kinase; MG: Methylglyoxal; mTOR: Mammalian target of rapamycin complex; $\mathrm{OPH}$ : Oxidized protein hydrolase; PD: Parkinson's disease; Pfkfb3: 6phosphofructo-2-kinase/fructose 2,6-bisphosphatase.

\section{Competing interests}

The authors declare that they have no competing interests.

\section{Authors' contributions}

All authors contributed to drafting the manuscript. All authors read and approved the final manuscript.

\section{Authors' information}

$\mathrm{ARH}$ is a visiting researcher at Aston Research Centre for Healthy Ageing (ARCHA); SPC is a PhD student supported by a BBSRC Targeted Priority Studentship in Ageing in RMB's laboratory; CB is an undergraduate student studying Biomedical Sciences at Aston University, on a placement year in RMB's laboratory; SRG is a Lecturer in Cell Biology in the School of Life and Health Sciences at Aston University; RMB is Professor of Biotechnology in the School of Life and Health Sciences at Aston University and sits on ARCHA's Internal Advisory Board.

\section{Acknowledgements}

SPC is supported by a BBSRC Targeted Priority Studentship in Ageing. Research in RMB's laboratory is supported by EPSRC, BBSRC, the Wellcome Trust and the European Commission.

Received: 2 November 2012 Accepted: 7 February 2013 Published: 25 February 2013

\section{References}

1. McFarland GA, Holliday R: Retardation of the senescence of cultured human diploid fibroblasts by carnosine. Exp Cell Res 1994, 212:167-175.

2. Holliday R, McFarland GA: Inhibition of the growth of transformed and neoplastic cells by the dipeptide carnosine. Br J Cancer 1996, 73:966-971.

3. Bauer K: Carnosine and homocarnosine, the forgotten, enigmatic peptides of the brain. Neurochem Res 2005, 30:1339-1345.

4. Boldyrev AA: Carnosine: new concept for the function of an old molecule. Biochemistry (Mosc) 2012, 77:313-326.

5. Dunnett $M$, Harris RC: High-performance liquid chromatographic determination of imidazole dipeptides, histidine, 1-methylhistidine and 3-methylhistidine in equine and camel muscle and individual muscle fibres. J Chromatogr B Biomed Sci Appl 1997, 688:47-55.

6. Boldyrev A, Bulygina E, Leinsoo T, Petrushanko I, Tsubone S, Abe H: Protection of neuronal cells against reactive oxygen species by carnosine and related compounds. Comp Biochem Physiol B Biochem Mol Biol 2004, 137:81-88.
7. Fontana M, Pinnen F, Lucente G, Pecci L: Prevention of peroxynitritedependent damage by carnosine and related sulphonamido pseudodipeptides. Cell Mol Life Sci 2002, 59:546-551.

8. Aldini G, Granata P, Carini M: Detoxification of cytotoxic alpha, betaunsaturated aldehydes by carnosine: characterization of conjugated adducts by electrospray ionization tandem mass spectrometry and detection by liquid chromatography/mass spectrometry in rat skeletal muscle. J Mass Spectrom 2002, 37:1219-1228.

9. Hipkiss AR, Chana H: Carnosine protects proteins against methylglyoxalmediated modifications. Biochem Biophys Res Commun 1998, 248:28-32.

10. Hipkiss AR, Michaelis J, Syrris P: Non-enzymatic glycosylation of the dipeptide L-carnosine, a potential anti-protein-cross-linking agent. FEBS Lett 1995, 371:81-85.

11. Vistoli G, Orioli M, Pedretti A, Regazzoni L, Canevotti R, Negrisoli G, Carini M, Aldini G: Design, synthesis, and evaluation of carnosine derivatives as selective and efficient sequestering agents of cytotoxic reactive carbonyl species. ChemMedChem 2009, 4:967-975.

12. Trombley PQ, Horning MS, Blakemore LJ: Interactions between carnosine and zinc and copper: implications for neuromodulation and neuroprotection. Biochemistry (Mosc) 2000, 65:807-816

13. Abe $\mathrm{H}$ : Role of histidine-related compounds as intracellular proton buffering constituents in vertebrate muscle. Biochemistry (MosC) 2000, 65:757-765.

14. Ikeda D, Wada S, Yoneda C, Abe H, Watabe S: Carnosine stimulates vimentin expression in cultured rat fibroblasts. Cell Struct Funct 1999, 24:79-87.

15. Kulebyakin K, Karpova L, Lakonsteva E, Krasavin M, Boldyrev A: Carnosine protects neurons against oxidative stress and modulates the time profile of MAPK cascade signaling. Amino Acids 2012, 43:91-96.

16. Son DO, Satsu H, Kiso Y, Totsuka M, Shimizu M: Inhibitory effect of carnosine on interleukin-8 production in intestinal epithelial cells through translational regulation. Cytokine 2008, 42:265-276.

17. Hipkiss AR: Energy metabolism, proteotoxic stress and age-related dysfunction - protection by carnosine. Mol Aspects Med 2011, 32:267-278

18. Dang CV: Links between metabolism and cancer. Genes Dev 2012 26:877-890.

19. Granchi C, Minutolo F: Anticancer agents that counteract tumor glycolysis. ChemMedChem 2012, 7:1318-1350.

20. Warburg O: On respiratory impairment in cancer cells. Science 1956 124:269-270.

21. Funes JM, Quintero M, Henderson S, Martinez D, Qureshi U, Westwood C, Clements MO, Bourboulia D, Pedley RB, Moncada S, Boshoff C Transformation of human mesenchymal stem cells increases their dependency on oxidative phosphorylation for energy production. Proc Natl Acad Sci U S A 2007, 104:6223-6228.

22. Moreno-Sanchez R, Rodriguez-Enriquez S, Marin-Hernandez A, Saavedra E: Energy metabolism in tumor cells. FEBS J 2007, 274:1393-1418.

23. Ertel A, Tsirigos A, Whitaker-Menezes D, Birbe RC, Pavlides S, MartinezOutschoorn UE, Pestell RG, Howell A, Sotgia F, Lisanti MP: Is cancer a metabolic rebellion against host aging? In the quest for immortality, tumor cells try to save themselves by boosting mitochondrial metabolism. Cell Cycle 2012, 11:253-263.

24. Natter K, Kohlwein SD: Yeast and cancer cells - common principles in lipid metabolism. Biochim Biophys Acta 2013, 1831:314-326.

25. Renner C, Asperger A, Seyffarth A, Meixensberger J, Gebhardt R, Gaunitz F: Carnosine inhibits ATP production in cells from malignant glioma. Neurol Res 2010, 32:101-105.

26. Renner C, Zemitzsch N, Fuchs B, Geiger KD, Hermes M, Hengstler J, Gebhardt R, Meixensberger J, Gaunitz F: Carnosine retards tumor growth in vivo in an NIH3T3-HER2/neu mouse model. Mol Cancer 2010, 9:2.

27. Cartwright SP, Bill RM, Hipkiss AR: L-Carnosine Affects the Growth of Saccharomyces cerevisiae in a Metabolism-Dependent Manner. PLoS One 2012, 7:e45006.

28. Ikeda T, Kimura K, Hama T, Tamaki N: Activation of rabbit muscle fructose 1,6-bisphosphatase by histidine and carnosine. J Biochem 1980, 87:179-185.

29. Garfinkel L, Garfinkel D: Magnesium regulation of the glycolytic pathway and the enzymes involved. Magnesium 1985, 4:60-72.

30. Wallace DC: A mitochondrial paradigm for degenerative diseases and ageing. Novartis Found Symp 2001, 235:247-263.

31. Agathocleous M, Love NK, Randlett O, Harris JJ, Liu J, Murray AJ, Harris WA Metabolic differentiation in the embryonic retina. Nat Cell Biol 2012, 14:859-864. 
32. De Marchis S, Modena C, Peretto P, Migheli A, Margolis FL, Fasolo A: Carnosine-related dipeptides in neurons and glia. Biochemistry (MosC) 2000, 65:824-833.

33. Pognetto MS, Panzanelli P, Fasolo A, Cantino D: Expression of carnosinelike immunoreactivity during retinal development in the clawed frog (Xenopus laevis). Brain Res Dev Brain Res 1992, 70:134-138.

34. Baguet A, Everaert I, Achten E, Thomis M, Derave W: The influence of sex, age and heritability on human skeletal muscle carnosine content. Amino Acids 2012, 43:13-20

35. Grinio L, Stvolinsky SL: Carnosine and muscle pathologies. In International Congress on Exercise and Disease; Ghent. 2011:46.

36. Derave W, Everaert I, Beeckman S, Baguet A: Muscle carnosine metabolism and beta-alanine supplementation in relation to exercise and training. Sports Med 2010, 40:247-263.

37. Nekrasova OE, Mendez MG, Chernoivanenko IS, Tyurin-Kuzmin PA, Kuczmarski ER, Gelfand VI, Goldman RD, Minin AA: Vimentin intermediate filaments modulate the motility of mitochondria. Mol Biol Cell 2011, 22:2282-2289

38. Zakharchenko MV, Temnov AV, Kondrashova MN: Effect of carnosine on self-organization of mitochondrial assemblies in rat liver homogenate. Biochemistry (Mosc) 2003, 68:1002-1005.

39. Chondrogianni N, Gonos ES: Proteasome function determines cellular homeostasis and the rate of aging. Adv Exp Med Biol 2010, 694:38-46.

40. Lionaki E, Markaki M, Tavernarakis N: Autophagy and ageing: Insights from invertebrate model organisms. Ageing Res Rev 2013, 12:413-428.

41. Herbert AP, Riesen M, Bloxam L, Kosmidou E, Wareing BM, Johnson JR, Phelan MM, Pennington SR, Lian LY, Morgan A: NMR structure of Hsp12, a protein induced by and required for dietary restriction-induced lifespan extension in yeast. PLoS One 2012, 7:e41975.

42. Salway KD, Gallagher EJ, Page MM, Stuart JA: Higher levels of heat shock proteins in longer-lived mammals and birds. Mech Ageing Dev 2011, 132:287-297.

43. Hipkiss AR: On the mechanisms of ageing suppression by dietary restriction-is persistent glycolysis the problem? Mech Ageing Dev 2006, 127:8-15.

44. Uchiki T, Weikel KA, Jiao W, Shang F, Caceres A, Pawlak D, Handa JT, Brownlee M, Nagaraj R, Taylor A: Glycation-altered proteolysis as a pathobiologic mechanism that links dietary glycemic index, aging, and age-related disease (in nondiabetics). Aging Cell 2012, 11:1-13.

45. Hipkiss AR: Accumulation of altered proteins and ageing: causes and effects. Exp Gerontol 2006, 41:464-473.

46. Desai KM, Chang T, Wang H, Banigesh A, Dhar A, Liu J, Untereiner A, Wu L: Oxidative stress and aging: is methylglyoxal the hidden enemy? Can J Physiol Pharmacol 2010, 88:273-284.

47. Liu J, Wang R, Desai K, Wu L: Upregulation of aldolase B and overproduction of methylglyoxal in vascular tissues from rats with metabolic syndrome. Cardiovasc Res 2011, 92:494-503.

48. Aldini G, Orioli M, Rossoni G, Savi F, Braidotti P, Vistoli G, Yeum KJ, Negrisol G, Carini M: The carbonyl scavenger carnosine ameliorates dyslipidaemia and renal function in Zucker obese rats. J Cell Mol Med 2011, 15:1339-1354

49. Ohkawara T, Nishihira J, Nagashima R, Takeda H, Asaka M: Polaprezinc protects human colon cells from oxidative injury induced by hydrogen peroxide: relevant to cytoprotective heat shock proteins. World J Gastroenterol 2006, 12:6178-6181.

50. Mikami K, Otaka M, Watanabe D, Goto T, Endoh A, Miura K, Ohshima S, Yoneyama K, Sato M, Shibuya T, et al: Zinc L-carnosine protects against mucosal injury in portal hypertensive gastropathy through induction of heat shock protein 72. J Gastroenterol Hepatol 2006, 21:1669-1674.

51. Bonner AB, Swann ME, Marway JS, Heap LC, Preedy VR: Lysosomal and nonlysosomal protease activities of the brain in response to ethanol feeding. Alcohol 1995, 12:505-509.

52. Hipkiss AR, Brownson C, Bertani MF, Ruiz E, Ferro A: Reaction of carnosine with aged proteins: another protective process? Ann N Y Acad Sci 2002, 959:285-294.

53. Dehvari N, Mahmud T, Persson J, Bengtsson T, Graff C, Winblad B, Ronnback A, Behbahani $\mathrm{H}$ : Amyloid precursor protein accumulates in aggresomes in response to proteasome inhibitor. Neurochem Int 2012, 60:533-542.

54. Pilecka I, Sadowski L, Kalaidzidis Y, Miaczynska M: Recruitment of APPL1 to ubiquitin-rich aggresomes in response to proteasomal impairment. Exp Cell Res 2011, 317:1093-1107.
55. Shimizu K, Kiuchi Y, Ando K, Hayakawa M, Kikugawa K: Coordination of oxidized protein hydrolase and the proteasome in the clearance of cytotoxic denatured proteins. Biochem Biophys Res Commun 2004, 324:140-146.

56. Herrero-Mendez A, Almeida A, Fernandez E, Maestre C, Moncada S, Bolanos JP: The bioenergetic and antioxidant status of neurons is controlled by continuous degradation of a key glycolytic enzyme by APC/C-Cdh1. Nat Cell Biol 2009, 11:747-752.

57. Rodriguez-Rodriguez P, Fernandez E, Almeida A, Bolanos JP: Excitotoxic stimulus stabilizes PFKFB3 causing pentose-phosphate pathway to glycolysis switch and neurodegeneration. Cell Death Differ 2012, 19:1582-1589.

58. Almeida A, Bolanos JP, Moncada S: E3 ubiquitin ligase APC/C-Cdh1 accounts for the Warburg effect by linking glycolysis to cell proliferation. Proc Natl Acad Sci U S A 2010, 107:738-741.

59. Hipkiss AR: Carnosine and its possible roles in nutrition and health. $A d v$ Food Nutr Res 2009, 57:87-154.

60. Maher PA, Schubert DR: Metabolic links between diabetes and Alzheimer's disease. Expert Rev Neurother 2009, 9:617-630.

61. Mai A: Revelations into resveratrol's mechanism. Nat Med 2012, 18:500-501.

62. Babizhayev MA, Seguin MC, Gueyne J, Evstigneeva RP, Ageyeva EA, Zheltukhina GA: L-carnosine (beta-alanyl-L-histidine) and carcinine (beta-alanylhistamine) act as natural antioxidants with hydroxyl-radical -scavenging and lipid-peroxidase activities. Biochem J 1994, 304(Pt 2):509-516.

63. Baran EJ: Metal complexes of carnosine. Biochemistry (Mosc) 2000, 65:789-797.

64. Kohen R, Yamamoto Y, Cundy KC, Ames BN: Antioxidant activity of carnosine, homocarnosine, and anserine present in muscle and brain. Proc Natl Acad Sci U S A 1988, 85:3175-3179.

65. Chengappa KN, Turkin SR, DeSanti S, Bowie CR, Brar JS, Schlicht PJ, Murphy $\mathrm{SL}$, Hetrick ML, Bilder R, Fleet D: A preliminary, randomized, double-blind, placebo-controlled trial of L-carnosine to improve cognition in schizophrenia. Schizophr Res 2012, 142:145-152.

66. Boldyrev AA, Gallant SC, Sukhich GT: Carnosine, the protective, anti-aging peptide. Biosci Rep 1999, 19:581-587.

67. Gaunitz F, Hipkiss AR: Carnosine and cancer: a perspective. Amino Acids 2012, 43:135-142.

68. Scheper GC, Proud CG: Does phosphorylation of the cap-binding protein elF4E play a role in translation initiation? Eur J Biochem 2002, 269:5350-5359.

69. Yellen P, Saqcena M, Salloum D, Feng J, Preda A, Xu L, Rodrik-Outmezguine $\checkmark$, Foster DA: High-dose rapamycin induces apoptosis in human cancer cells by dissociating mTOR complex 1 and suppressing phosphorylation of 4E-BP1. Cell Cycle 2011, 10:3948-3956.

70. Villa-Cuesta E, Boylan JM, Tatar M, Gruppuso PA: Resveratrol inhibits protein translation in hepatic cells. PLoS One 2011, 6:e29513.

71. Logsdon CD, Fuentes MK, Huang EH, Arumugam T: RAGE and RAGE ligands in cancer. Curr Mol Med 2007, 7:777-789.

72. Abe R, Yamagishi S: AGE-RAGE system and carcinogenesis. Curr Pharm Des 2008, 14:940-945.

73. Pietkiewicz J, Bronowicka-Szydelko A, Dzierzba K, Danielewicz R, Gamian A: Glycation of the muscle-specific enolase by reactive carbonyls: effect of temperature and the protection role of carnosine, pyridoxamine and phosphatidylserine. Protein J 2011, 30:149-158.

74. Alhamdani MS, Al-Kassir AH, Abbas FK, Jaleel NA, Al-Taee MF: Antiglycation and antioxidant effect of carnosine against glucose degradation products in peritoneal mesothelial cells. Nephron Clin Pract 2007, 107:c26-c34.

75. Alhamdani MS, Al-Azzawie HF, Abbas FK: Decreased formation of advanced glycation end-products in peritoneal fluid by carnosine and related peptides. Perit Dial Int 2007, 27:86-89.

76. Bellia F, Vecchio G, Cuzzocrea S, Calabrese V, Rizzarelli E: Neuroprotective features of carnosine in oxidative driven diseases. Mol Aspects Med 2011 32:258-266.

77. Hipkiss AR: Dietary restriction, glycolysis, hormesis and ageing. Biogerontology 2007, 8:221-224.

78. Hipkiss AR: Could carnosine or related structures suppress Alzheimer's disease? J Alzheimers Dis 2007, 11:229-240.

79. Preston JE, Hipkiss AR, Himsworth DT, Romero IA, Abbott JN: Toxic effects of beta-amyloid(25-35) on immortalised rat brain endothelial cell: 
protection by carnosine, homocarnosine and beta-alanine. Neurosci Lett 1998, 242:105-108.

80. Fu Q, Dai H, Hu W, Fan Y, Shen Y, Zhang W, Chen Z: Carnosine protects against Abeta42-induced neurotoxicity in differentiated rat PC12 cells. Cell Mol Neurobiol 2008, 28:307-316.

81. Munch G, Mayer S, Michaelis J, Hipkiss AR, Riederer P, Muller R, Neumann A, Schinzel R, Cunningham AM: Influence of advanced glycation endproducts and AGE-inhibitors on nucleation-dependent polymerization of beta-amyloid peptide. Biochim Biophys Acta 1997, 1360:17-29.

82. Corona C, Frazzini V, Silvestri E, Lattanzio R, La Sorda R, Piantelli M, Canzoniero LM, Ciavardelli D, Rizzarelli E, Sensi SL: Effects of dietary supplementation of carnosine on mitochondrial dysfunction, amyloid pathology, and cognitive deficits in 3xTg-AD mice. PLoS One 2011, 6:e17971.

83. Scozzafava A, Supuran CT: Carbonic anhydrase activators: high affinity isozymes I, II, and IV activators, incorporating a beta-alanyl-histidine scaffold. J Med Chem 2002, 45:284-291.

84. Kida E, Palminiello S, Golabek AA, Walus M, Wierzba-Bobrowicz T, Rabe A, Albertini G, Wisniewski KE: Carbonic anhydrase II in the developing and adult human brain. J Neuropathol Exp Neurol 2006, 65:664-674.

85. Fasseas MK, Tsikou D, Flemetakis E, Katinakis P: Molecular and biochemical analysis of the alpha class carbonic anhydrases in Caenorhabditis elegans. Mol Biol Rep 2011, 38:1777-1785.

86. Boldyrev A, Fedorova T, Stepanova M, Dobrotvorskaya I, Kozlova E, Boldanova N, Bagyeva G, Ivanova-Smolenskaya I, Illarioshkin S: Carnosine [corrected] increases efficiency of DOPA therapy of Parkinson's disease: a pilot study. Rejuvenation Res 2008, 11:821-827.

87. Boldyrev AA, Stvolinsky SL, Fedorova TN, Suslina ZA: Carnosine as a natural antioxidant and geroprotector: from molecular mechanisms to clinical trials. Rejuvenation Res 2010, 13:156-158.

88. Licker V, Cote M, Lobrinus JA, Rodrigo N, Kovari E, Hochstrasser DF, Turck N, Sanchez JC, Burkhard PR: Proteomic profiling of the substantia nigra demonstrates CNDP2 overexpression in Parkinson's disease. J Proteomics 2012, 75:4656-4667.

89. Deng Y, Zhang Y, Li Y, Xiao S, Song D, Qing H, Li Q, Rajput AH: Occurrence and distribution of salsolinol-like compound, 1-acetyl-6,7-dihydroxy1,2,3,4-tetrahydroisoquinoline (ADTIQ) in parkinsonian brains. J Neural Transm 2012, 119:435-441.

90. Kang JH: Salsolinol, a catechol neurotoxin, induces modification of ferritin: Protection by histidine dipeptide. Environ Toxicol Pharmacol 2010, 29:246-251.

91. Hipkiss AR: Parkinson's Disease and Type-2 Diabetes: Methylglyoxal may be a Common Causal Agent; Carnosine could be Protective. Mol Med Ther 2012, 1:2

92. Kumar PA, Kumar MS, Reddy GB: Effect of glycation on alpha-crystallin structure and chaperone-like function. Biochem J 2007, 408:251-258.

93. Kim J, Sohn E, Kim CS, Kim JS: Renal podocyte apoptosis in Zucker diabetic fatty rats: involvement of methylglyoxal-induced oxidative DNA damage. J Comp Pathol 2011, 144:41-47.

94. Negre-Salvayre A, Salvayre R, Auge N, Pamplona R, Portero-Otin M: Hyperglycemia and glycation in diabetic complications. Antioxid Redox Signal 2009, 11:3071-3109.

95. Aviles-Olmos I, Limousin P, Lees A, Foltynie T: Parkinson's disease, insulin resistance and novel agents of neuroprotection. Brain 2013, 136:374-384.

96. Vincent A, Briggs L, Chatwin GF, Emery E, Tomlins R, Oswald M, Middleton CA, Evans GJ, Sweeney ST, Elliott CJ: Parkin-induced defects in neurophysiology and locomotion are generated by metabolic dysfunction and not oxidative stress. Hum Mol Genet 2012, 21:1760-1769.

97. Wahlqvist ML, Lee MS, Hsu CC, Chuang SY, Lee JT, Tsai HN: Metformininclusive sulfonylurea therapy reduces the risk of Parkinson's disease occurring with Type 2 diabetes in a Taiwanese population cohort. Parkinsonism Relat Disord 2012, 18:753-758.

98. Rabbani N, Thornalley PJ: Methylglyoxal, glyoxalase 1 and the dicarbonyl proteome. Amino Acids 2012, 42:1133-1142.

99. Hipkiss AR: Would carnosine or a carnivorous diet help suppress aging and associated pathologies? Ann N Y Acad Sci 2006, 1067:369-374.

100. Bierhaus A, Fleming T, Stoyanov S, Leffler A, Babes A, Neacsu C, Sauer SK, Eberhardt M, Schnolzer M, Lasitschka F, et al: Methylglyoxal modification of Nav1.8 facilitates nociceptive neuron firing and causes hyperalgesia in diabetic neuropathy. Nat Med 2012, 18:926-933.
101. Eberhardt MJ, Filipovic MR, Leffler A, de la Roche J, Kistner K, Fischer MJ, Fleming T, Zimmermann K, Ivanovic-Burmazovic I, Nawroth PP, et al: Methylglyoxal Activates Nociceptors through Transient Receptor Potential Channel A1 (TRPA1): a possible mechanism of metabolic neuropathies. J Biol Chem 2012, 287:28291-28306.

102. Kamei J, Ohsawa M, Miyata S, Tanaka S: Preventive effect of L-carnosine on changes in the thermal nociceptive threshold in streptozotocininduced diabetic mice. Eur J Pharmacol 2008, 600:83-86.

103. Ohsawa M, Mutoh J, Asato M, Yamamoto S, Ono H, Hisa H, Kamei J: Carnosine has antinociceptive properties in the inflammation-induced nociceptive response in mice. Eur J Pharmacol 2012, 682:56-61.

104. Everaert I, Taes Y, De Heer E, Baelde H, Zutinic A, Yard B, Sauerhofer S, Vanhee L, Delanghe J, Aldini G, Derave W: Low plasma carnosinase activity promotes carnosinemia after carnosine ingestion in humans. Am J Physiol Renal Physiol 2012, 302:F1537-F1544.

doi:10.1186/1752-153X-7-38

Cite this article as: Hipkiss et al.: Carnosine: can understanding its actions on energy metabolism and protein homeostasis inform its therapeutic potential?. Chemistry Central Journal 2013 7:38.

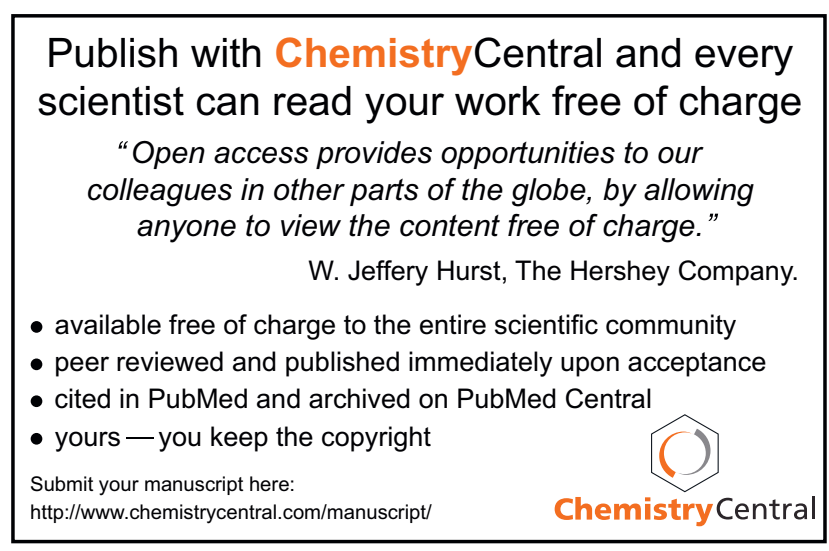

